\title{
Analysis on the Influence of Fiscal and Taxation Policies on New Urbanization
}

\author{
Yanjun Yang \\ School of accounting, ZIBO Vocational institute, Zibo, Shandong, China \\ 346499808@qq.com
}

\begin{abstract}
With the upgrading and improvement of industrial structure, the construction of new urbanization will eventually promote the overall economic development of the society and increase the national tax revenue. Based on the analysis of the impact of fiscal and tax policies on new urbanization, this paper puts forward relevant suggestions for the problems existing in the process of supporting the development of new urbanization by fiscal and tax policies.
\end{abstract}

Keywords: finance, taxation, policy, new urbanization

\section{INTRODUCTION}

On May 22, 2020, Premier Li Keqiang proposed to strengthen the construction of new urbanization in the 2020 work report of the State Council. In the process of continuously promoting the construction of new urbanization, China should constantly optimize the tax policy to make it play its due role in economic construction.

\section{THE INFLUENCE OF FISCAL AND TAXATION POLICIES ON NEW URBANIZATION}

\subsection{There is an interactive relationship between fiscal and taxation policies and the construction of new urbanization}

The construction of new urbanization needs higher development cost, which is reflected in the fact that farmers and citizens enjoy the same social security and welfare system. If there is no strong fiscal and tax policy support, then the urbanization construction will be just on paper. Therefore, the process of urbanization needs a lot of financial investment from the government. Under the condition of insufficient investment in urbanization construction, the improvement of people's livelihood will be affected to a certain extent, and then affect people's quality of life. At the same time, the economic gap between urban and rural areas will continue to expand. In this situation, increasing the support of fiscal and tax policies not only reflects the people-oriented development concept, but also practices the scientific concept of development and promotes the socialist economy development. In addition, with the strong support of fiscal and tax policies, we should further promote the management of urbanization to be more refined, improve the infrastructure construction of urbanization, realize the modernization of infrastructure management, and pay attention to what residents want instead of forced or violent demolition, so as to ultimately achieve the goal of improving the quality of life.

In the process of new urbanization, it is the most important task to realize the equalization of public services between urban and rural areas. If the problem of equalization of public services between urban and rural areas cannot be solved, the development goal of urbanization will be difficult to achieve, and even cause many social equity problems, which will cause people's dissatisfaction seriously, which is not conducive to the construction of new urbanization[1]. In the construction of new urbanization, it is also necessary to take into account the principle of urban and rural integration, establish new regional industrial chain and new local taxes. The cultivation of local taxes can promote the good interaction between urbanization and financial expenditure, and build a systematic local tax system. This way not only optimizes the local tax structure, but also increases the local tax revenue. Moreover, scientific fiscal and tax policies can promote the rational allocation of human, financial and material resources, and then adjust the regional industrial structure reasonably to ensure that the industrial structure matches the process of urbanization. In the process of 
making fiscal and tax policies, we should formulate corresponding tax rates for different industrial properties, correctly guide the flow direction of capital, and accelerate the continuous upgrading of industrial structure.

\subsection{Scientific fiscal and tax policy is the booster of new urbanization construction}

Scientific fiscal and tax policies provide financial support for the development of new urbanization, but also promote the optimal allocation of resources to ensure that the construction of urbanization can be carried out to the end. With the continuous optimization and upgrading of the industrial structure, in addition to China's efforts to adjust the direction of industrial policies, especially the rapid development of the new service industry chain, broaden the channels for the government to increase fiscal revenue, increase the national tax revenue, and ensure the development of new urbanization has sufficient financial funds. Scientific fiscal and tax policies promote the development of new urbanization, not only in terms of funds, but also in production factors. China's new urbanization construction and the modernization of the primary industry and the innovation of the secondary industry mode complement each other. In the process of the modernization of the primary industry and the innovation of the mode of the secondary industry, there are a large number of labor, land and other production factors. The development of new urbanization in China adheres to the "citizenization of farmers" as the core, and the scientific fiscal and tax policies are used to reasonably regulate labor Power, land and other production factors can promote the rational flow of production factors among different industries. The reasonable flow of production factors can greatly improve the development quality of urbanization.

In addition, scientific fiscal and tax policies can help improve the quality of new urbanization[2]. The construction of new urbanization needs long-term development, and it is necessary to take into account the protection of ecological system. Therefore, scientific fiscal and tax policies should be used to reasonably allocate ecological resources, strengthen the protection of ecological system, and improve the speed of ecosystem restoration, so as to make urbanization "new + green" combined into one, so as to ensure the long-term and green development of new urbanization. This will also promote the reform of fiscal and taxation policies, adapt to the development of new urbanization, and ultimately realize the sustainable development of urbanization quality. With the strong support of fiscal and tax policies, the quality education of farmers is also accompanied by development, which can promote the improvement of farmers' cultural quality and exercise more vocational skills, provide more opportunities for their survival and development in the city, and provide talent support for the industrial development of urbanization areas.

\section{PROBLEMS IN THE PROCESS OF FINANCIAL AND TAX POLICIES SUPPORTING THE DEVELOPMENT OF NEW URBANIZATIOM}

\subsection{The financing system is not perfect}

The financing system of most local governments in China is not enough to support the development of new urbanization. There are some problems such as low financing capacity, single channel and unreasonable structure[3]. In this case, local governments obtain funds by transferring land, and many governments raise funds for new urbanization mainly from land finance. However, the income from land finance, due to the problems in the process of land acquisition and demolition compensation is not handled properly, its adverse impact extends to the social level, and to a certain extent affects the quality of China's new urbanization construction. With the help of financing platform, it mainly loans to large state-owned enterprises or state-owned banks. The financing channels are very single, which greatly reduces the ability of local governments to cope with the changes of new urbanization construction policies, and the financing capacity is limited, which is easy to cause the situation of capital shortage. Especially for the first level township government, its financial resources are very limited, it is difficult to raise the funds needed for the construction of new urbanization. Most of them are only enough to maintain daily expenses, and there are many restrictions on bank loans, which lead to the flooding of three financing modes: soil financing, borrowing and fund-raising. The lack of flexibility of local financing mechanism has become a bottleneck in promoting the construction of new urbanization in China.

\subsection{The local tax system is unreasonable}

From the perspective of the improvement process of the current fiscal and taxation system, the urban governments in China are unable to have the legislative power of local taxes, which to a certain extent weakens the enthusiasm and initiative of local governments to increase fiscal revenue and regulate local economy. The proportion of property tax is relatively low, and there is a mismatch between financial power and administrative power. The limited local income can not meet the capital needs of urbanization construction. The fiscal and tax revenue of government departments is in short supply. At the same time, the investment and financing system of urban infrastructure construction is not perfect, and private capital is difficult to enter. On the one hand, it restricts the development of cities and towns, on the 
other hand, hinders the normal operation of cities and towns, and then affect the process of urbanization. In a word, there are many irrationalities in the process of making the local tax system, which is not enough to effectively support the financial expenditure of the new urbanization construction.

In China's current preferential tax policies, there are no clear requirements for the formulation of preferential objects, which leads to the lack of high-quality work efficiency in the implementation process of preferential policies, the decline of the implementation strength and control ability of fiscal and taxation policies, and the mismatch with the requirements of new urbanization construction, resulting in endless problems in the implementation process of preferential policies, but they can not be effectively solved Those who do not get the preferential treatment, but those who should enjoy the preferential treatment. As the implementation of fiscal and tax policies and the effect of regulation are not ideal, resulting in poor supply capacity of urban infrastructure, but also reducing the government's financial absorption. Some township governments are keen on land finance. At present, most cities in China lack of leading and high-tech intensive enterprises. The modernization of the primary industry has not formed a agglomeration effect, which aggravates the tension between revenue and expenditure of local financial resources, weakens the enthusiasm of the local government to regulate the industrial balance, seriously hinders the industrial balance required in the construction of new urbanization, and ultimately is not conducive to the new type Urbanization construction.

\section{COUNTERMEASURES OF FISCAL AND TAXATION POLICIES SUPPORTING THE DEVELOPMENT OF NEW URBANIZATIOM}

\subsection{Broaden the financing channels of new urbanization construction, realize the simultaneous development of multi financing and ensure sufficient funds [4]}

Behind the further development of new urbanization is the mutual support of governments at all levels and the concerted efforts of the people. In order to understand the financing difficulties of local governments and ensure that the financing can support the construction of new urbanization, innovative bond varieties should be created. For example, special bonds for local urbanization development are issued to encourage local governments to carry out infrastructure construction such as shantytowns transformation, land reserve projects, and highway transportation. At the same time, we should optimize the regulatory role of the government in guiding the market, take the government as the leading role, and make use of its high reputation to enhance the strength of financing private capital. In addition, it is also necessary to strengthen the supervision of the government, ensure the reasonable and orderly operation of financing projects and funds, and comprehensively build a reasonable structure of financing platform in multiple channels and forms. Or efficient use of green financial bonds for the purchase of environmental protection building materials in the construction of new urbanization, the construction of green transportation roads and the development of green industry financing projects.

\subsection{Optimize the local tax system of new urbanization construction}

Although the current financial and tax system construction in China still cannot give the local government the legislative power of local tax, in order to comprehensively promote the process of new urbanization, it is time to optimize the local tax system. The specific measures to optimize the local tax system are as follows: first, it is necessary to establish the principle of matching administrative power with financial power and clarify the scope of taxation. Second, the scope of local government jurisdiction should be appropriately relaxed, new taxes should be encouraged, tax rates should be set up reasonably and legally, and preferential tax policies should be opened up as green channels. In this way, the construction of new urbanization can achieve the same level of regional economic development. Third, on the basis of the overall planning of funds, the establishment of new taxes and reasonable consideration of the interests of the people, especially related to the "three rural" issues in the construction of new urbanization[5], should be given priority to properly deal with and make reasonable compensation for funds, so as to realize the equalization of public services between urban and rural areas and the citizenization of farmers, and provide strong support for the construction of new towns. Fourth, we should strengthen the reform of the tax system, form a basic local tax system suitable for the process of new urbanization, fully guarantee the legitimacy of Local Taxation from the tax system, and scientifically arrange the distribution proportion of the new urbanization construction in the financial revenue.

\section{CONCLUSION}

With the upgrading and improvement of the industrial structure, the construction of new urbanization will eventually promote the overall economic development of society and increase the fiscal and tax funds; and fiscal and tax funds are the necessary conditions for the construction of new urbanization, which will help to better realize the promotion of new urbanization. Promoting the reform of fiscal and taxation policies, optimizing the current fiscal and 
taxation system, and adapting to the development of new urbanization can better promote the new urbanization with Chinese characteristics, and ultimately achieve the sustainable development of urbanization quality.

\section{REFERENCES}

[1] L.H.Zheng. (2020) Suggestions on fiscal and taxation policies to promote the development of urbanization in China. J. Tax research,02: 113-119.
[2] H.M.Zhang. (2016) Discussion on the role of fiscal and tax policies in the development of new urbanization. J. China collective economy, 33: 5-6.

[3] R.Yang. (2017) Research on fiscal and tax policies to promote the development of new urbanization. J. Financial circles (Academic Edition), 13: 126-127.

[4] T.He. (2016) Research on fiscal and tax policies to promote the development of new urbanization. J. Agricultural economy, 11: 91-93.

[5] S.J.Wang. (2017) How fiscal and taxation reform can help the construction of new urbanization. J. People's forum, 15: 80-82. 